\title{
Do caranguejo vermelho ao Cristo cor-de-rosa: as campanhas educativas para a prevenção do câncer no Brasil
}

\author{
From red crab to pink Christ statue: cancer prevention \\ education campaigns in Brazil
}

\section{Vânia Rocha}

Coordenadora do Serviço de Educação em Ciências da Saúde/ Museu da Vida/

Casa de Oswaldo Cruz/Fundação Oswaldo Cruz

Av. Brasil, 4365 Manguinhos 21040-900 - Rio de Janeiro - RJ Brasil

vrocha@fiocruz.br
ROCHA, Vânia. Do caranguejo vermelho ao Cristo cor-derosa: as campanhas educativas para a prevenção do câncer no Brasil. História, Ciências, Saúde - Manguinhos, Rio de Janeiro, supl.1, jul. 2010, p.253-263.

\section{Resumo}

As campanhas de prevenção do câncer no Brasil são um aspecto importante da história do controle da doença. Os materiais produzidos no decorrer dessa história são uma rica fonte de documentos que merecem o olhar de profissionais de áreas como educação, comunicação, informação, saúde pública, história e hivulgação científica. Partindo desse pressuposto, analisam-se materiais de campanhas educativas a partir de distintos campos do conhecimento. As notas relatadas são fruto de análise preliminar de cartazes utilizados em campanhas. Este estudo foi realizado sob o enfoque da história da educação em saúde e será aprofundado nas próximas etapas da pesquisa.

Palavras-chaves: educação em saúde; história do câncer; campanhas de prevenção; materiais educativos; Brasil.

\section{Abstract}

Cancer prevention campaigns in Brazil are an important feature of the history of efforts to control this disease. The material produced down through this history offers a rich source of documents that merit the attention of professionals in such areas as education, communication, information, public health, history, and scientific educational outreach. Starting from this premise, I have analyzed education campaign material coming from different fields of knowledge. My notes are the result of a preliminary analysis of campaign posters from the perspective of the history of health education. This research will befurther developed.

Keywords: health education; history of cancer; prevention campaigns; educational material; Brazil. 
$E^{s}$ ste artigo apresenta análise preliminar de materiais de campanhas utilizados na pre venção e controle do câncer no Brasil, sob o olhar das estratégias de educação em saúde que vigoraram a partir dos anos 1920. É parte integrante da pesquisa História, Ciência, Educação e Saúde: as Campanhas de Prevenção do Câncer no Contexto da Cancerologia no Brasil, que visa potencializar o surgimento de estudos sobre o controle da doença no Brasil.

A história do câncer no Brasil esteve muito relacionada ao esforço em controlar a doença via prevenção, associada ao desenvolvimento de tecnologias para detecção precoce e de práticas terapêuticas. $O$ sofrimento causado aos acometidos e a seus familiares e o alto custo destinado ao tratamento fizeram da doença objeto prioritário nas ações de prevenção promovidas pelo setor público de saúde (Teixeira, Fonseca, 2007).

Com base na análise dos materiais das campanhas contra a doença, como folhetos, cartazes e propagandas vinculadas nos meios de comunicação a partir dos anos 1940, percebemos a ampliação dos esforços objetivando sensibilizar as pessoas para o problema e, em especial, chamar a atenção para a detecção precoce como forma de controle. $\mathrm{Na}$ década de 1940, a imagem de um caranguejo vermelho, simbolizando a doença, era estampada em panfletos e cartazes como metáfora do risco e da necessidade de enfrentamento de um mal ainda pouco conhecido (Figura 1). Hoje, recursos altamente diversificados são utilizados para alertar a população sobre o risco da doença, a exemplo da iluminação especial da estátua do Cristo Redentor, mencionada adiante. A análise aqui efetuada, dos enfoques utilizados nas campanhas em diferentes momentos da história da doença, tem facilitado a compreensão dos desafios e dos limites das campanhas preventivas.

\section{Os estudos sobre o câncer no Brasil}

Estudos recentes sobre a história do câncer o caracterizam como um enorme desafio para a medicina, tendo permanecido por muito tempo como doença desconhecida. As perspectivas de tratamento, até o início do século passado, eram quase insignificantes e somente a partir desse período a doença passou a ser conhecida um pouco melhor.

Os tratamentos desenvolvidos ainda no início do século XX começaram a apresentar alguns resultados. Entretanto, o conhecimento cada vez mais preciso ampliava a extensão do mal e revelava a limitada capacidade da medicina da época em combatêlo. Esses fatores intensificavam o temor da sociedade, que passou a vêlo como o flagelo da modernidade (Teixeira, Fonseca, 2007).

Os esclarecimentos a respeito da doença e a capacidade de desenvolvimento de novas práticas terapêuticas resultaram em parte da associação da medicina a outras áreas de pesquisa, como a física, a química e a biologia. Anteriormente, as alternativas de tratamento se restringiam a cirurgias de pouco efeito, como a extirpação do tumor, de órgãos e tecidos lesionados.

As grandes transformações em relação ao tratamento, no início do século $X X$, vieram da aproximação com a física e a química. O surgimento do raio X, em 1895, foi um grande passo nesse caminho. Médicos se apropriaram da técnica, encantados com a capacidade de diagnosticar a doença, e passaram a testá-la em busca da cura. A utilização da radioterapia 
em órgãos afetados parecia promissora, mesmo sem uma compreensão mais ampla do efeito biológico da técnica. No Brasil a técnica foi recebida com interesse diagnóstico, não tendo registro de trabalhos sobre uso terapêutico até meados da década de 1910 (Teixeira, Fonseca, 2007).

No entanto, o uso terapêutico da radiologia não foi ignorado por muito tempo pela medicina brasileira. Em 1922 foi inaugurado, na capital mineira, o Instituto Radium, voltado para pesquisa e tratamento do câncer, tendo como principal objetivo a promoção de estudos sobre o rádio e outros elementos radioativos para aplicação em tratamentos. Criado como fundação autônoma, tinha também a tarefa de divulgar conhecimentos sobre a doença ao público (Fenelon, Almeida, 2001).

As dificuldades de tratamento e cura exigiam o desenvolvimento de ações preventivas e levaram os profissionais envolvidos no combate a considerar a prevenção não apenas como medida necessária para evitar novos casos, mas como a principal al ternativa enquanto se buscava a cura.

O conhecimento científico produzido em torno da doença não foi fator isolado no avanço da prevenção. Estudos médicos em décadas anteriores revelavam o aumento de incidência no Brasil e reforçavam o interesse da medicina nacional pela doença, resultando num caminho ascendente para o seu reconhecimento como problema de saúde pública, a partir da década de 1920 (Teixeira, Fonseca, 2007).

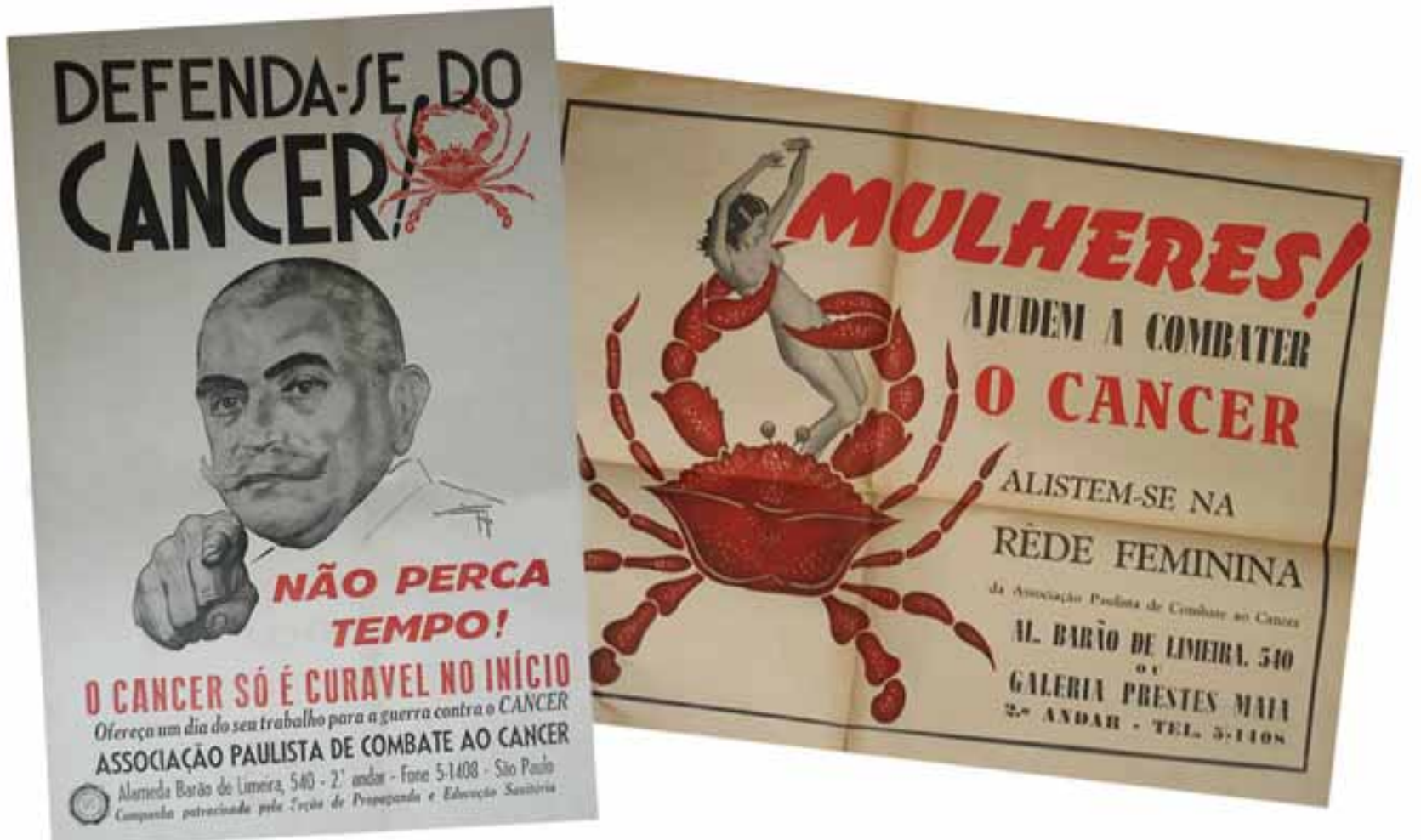

Figura 1: Cartazes utilizados pela Associação Paulista de Combate ao Câncer. (acervo Museu de Saúde Pública de São Paulo) 
Nesse período, a prioridade no combate a doenças estava voltada para as grandes epidemias que assolavam o país como a malária, a tuberculose e a sífilis, doenças vistas como obstáculo ao progresso. O desconhecimento sobre o câncer tornava-o suspeito de se tratar de uma doença contagiosa e por esse motivo desencadeou-se o aumento do interesse por medidas preventivas.

É nesse contexto que se iniciam as campanhas na agenda do setor público, com objetivo de levar à população informações sobre as possibilidades de tratamento e cura quando detectado precocemente e de evitar os abusos provocados pelo charlatanismo. Nesse mesmo período cresce o número de fundações, ligas de combate e institutos filantrópicos, que conduziam também iniciativas de apoio à prevenção (Teixeira, Fonseca, 2007).

No entanto, as ações voltadas ao controle do câncer foram mais efetivas a partir de 1940, com a atuação do médico Mário Kroeff. A cirurgia elétrica, técnica introduzida por Kroeff, trouxe novas perspectivas ao tratamento e suas iniciativas em torno da prevenção da doença foram reconhecidas nacionalmente. Em análise da literatura sobre seu trabalho, podemos encontrar iniciativas na formação de profissionais para atuarem na área da cancerologia, na melhoria do atendimento aos acometidos, na atenção social aos casos de pacientes terminais e na diversidade de estratégias destinadas a levar informações à população (Kroeff, 1947).

A biologia celular e molecular contribuiu para o entendimento dos mecanismos de desenvolvimento dos tumores por divisão celular e para a consolidação das recentes técnicas de tratamento. No entanto, esses estudos ocorreram somente nas últimas décadas, e a ausência de cura reforça a importância das ações preventivas.

\section{Educação em saúde no Brasil e as campanhas de prevenção do câncer}

Segundo registros da 10ạ Conferência Nacional de Saúde, realizada em 1996, as primeiras iniciativas educativas configuradas como programas de educação em saúde no país datam de 1924, com a criação do Pelotão de Saúde, que atuava em uma escola estadual em São Gonçalo, no Rio de Janeiro. No ano seguinte o mesmo modelo foi adotado em escolas primárias do antigo Distrito Federal. Ainda em 1925 foi inaugurada, em São Paulo, a Inspetoria de Educação Sanitária e Centros de Saúde, com a finalidade de promover a formação da consciência sanitária da população e dos serviços de profilaxia geral e específica. Pela primeira vez o título de educador sanitário foi mencionado; seu papel era levar noções de higiene para alunos de escolas primárias. A partir dessas iniciativas, outras semelhantes surgiram no Brasil, como a criação da Inspetoria de Educação Sanitária do Departamento de Saúde e Assistência em Pernambuco (Brasil, 1996).

Investigan do as iniciativas de educação em saúde desse período, registradas em literatura (Melo, 1981; Mohr, Schall, 1992; Rocha, 2003), percebemos a centralização das ações em um modelo medicalizador da vida social, embasado no controle do Estado sobre os indivíduos, por influência dos avanços da bacteriologia e sob enfoque da higiene. A ordem era sanear, monitorar e prevenir doenças, reduzindo suas causas e efeitos ao controle biológico. As informações levadas à população por meio de cartilhas, panfletos e propagandas vinculadas no rádio eram também pautadas nesse modelo. 
Essa era também a ten dência das ações preventivas em outros países. Petersen e Lupton (1996), em análise sobre o discurso de risco, constatam que a higiene, como estratégia de saúde, considerava o ambiente das cidades como 'objeto medical izável'. Esse era o discurso da saúde pública na Inglaterra, Austrália e nos Estados Unidos no final do século XIX. No Brasil, as medidas de prevenção e educação sanitária foram influenciadas por essa ordem e eram caracterizadas pela criação de unidades especializadas em epidemias (M elo, 1981).

Esse foi um dos motivos que levaram as iniciativas de educação em saúdea permanecerem por muito tempo voltadas ao controle dos hábitos da população por meio da higiene (Rocha, 2003). Os materiais utilizados eram então centrados em informações básicas, padronizadas e de al cance limitado (Schall, 1999). Embora importante para a aprendizagem sobre doenças e como forma de evitar epidemias, a abordagem voltada à higiene reduzia os problemas de saúde ao controle de agentes biológicos causadores ou transmissores de doenças, responsabilizando somente o sujeito pela sua condição de saúde.

No que se refere à preven ção do câncer, na década de 1920 existiam materiais vinculados como propaganda, por meio de cartazes, folhetos, conferências, palestras, programas de rádio, além de enfermei ras visitadorasque levavam informações àsfamílias sob seus cuidados.

Entretanto, as ações mais efetivas foram estabelecidas no início dos anos 1940, a partir da atuação do médico Mário Kroeff como diretor do Serviço Nacional do Câncer. Kroeff tornou a prevenção uma atividade fundamental entre as ações de combate à doença. Incentivou campanhas que utilizavam diversificadas estratégias e envolveu profissionais de diferentes áreas nas ações educativas (Kroeff, 1947).

A preocupação estava também centrada em formar médicos de regiões distantes do país, fazendo com que informações circulassem via Rádio Ministério da Educação e Saúde, que transmitia palestras e conferências, a partir de 1942. Um filme produzido pelo próprio Mário Kroeff foi elaborado com essa função (Carvalho, 2006).

Em consonância com esses fatos, a grande mudança de visão em torno das atividades de educação sanitária no país ocorreu nos anos 1940. Antes, as ações eram centradas na produção de materiais impressos, muitas vezes destinados a um público analfabeto e elaborado sem a preocupação de identificar quem seria o receptor da informação. A partir de 1942, a educação sanitária passa a formar educadores para tal função, em especial professoras da rede pública de ensino e agentes educacionais da saúde, incentivando o contato humano como elemento importante do processo educativo (Brasil, 1996).

As mudanças no âmbito da educação sanitária, no início dos anos 1940, expressam as transformações ocorridas na saúde pública no período. As ações em saúde tiveram maior abrangência e incluíram o combate a várias doenças, entre elas o câncer. Foram também criados os Serviços Nacionais de Saúde, que incorporavam a nova organização do Departamento Nacional de Saúde. O objetivo desses serviços era controlar surtos epidêmicos e estabelecer métodos de prevenção em conjunto com delegacias federais de saúde e com governos locais. Dos 12 serviços criados, o Serviço Nacional de Educação Sanitária tinha a função principal de "vulgarizar preceitos de higiene e saúde pública" com o intuito de "infundir, formar e desenvolver a consciência sanitária do povo" (Fonseca, 2007).

Em um olhar analítico para as abordagens utilizadas nos materiais desse período, destinados à prevenção do câncer, são evidenciadas estratégias para chamar a atenção da 
população sobre o risco e o combate contra um mal. A figura de um caranguejo vermelho é recorrente nos cartazes e folhetos, simbolizando a doença, como se estivesse pronto para acometer qualquer pessoa com seus 'múltiplos braços' (Figuras 2 e 3). 0 combate era representado por elementos bélicos como espadas e punhais levantados contra a doença. As exposições eram sequências de fotos de pacientes apresentando tumores, muitos em estágios avançados, como forma de sensibilizar para a detecção precoce. A ideia principal era mostrar que o mal era terrível, mas podia ser combatido quando detectado em tempo.

Em nossas análises percebemos que as campanhas educativas de prevenção do câncer seguem a lógica da educação sanitária que vigorou no país do início até meados dos anos 1950. A atenção para o risco e o controle por estratégias intervencionistas estavam presentes nos materiais produzidos, com intenção de melhorar os níveis de saúde da população, num país que caminhava rumo à industrialização.

Entre 1950 e 1960 houve um período áureo da educação sanitária no Brasil, que articulou saúde e educação, resultando em avanços institucionais significativos. Atenção à saúde mental, ações voltadas à saúde da criança com a implantação de escolas maternais e creches são al guns exemplos de investimentos pautados no movimento de suporteà industrial ização que vivia o país (Mohr, Schall, 1992). A participação das comunidades nos processos de
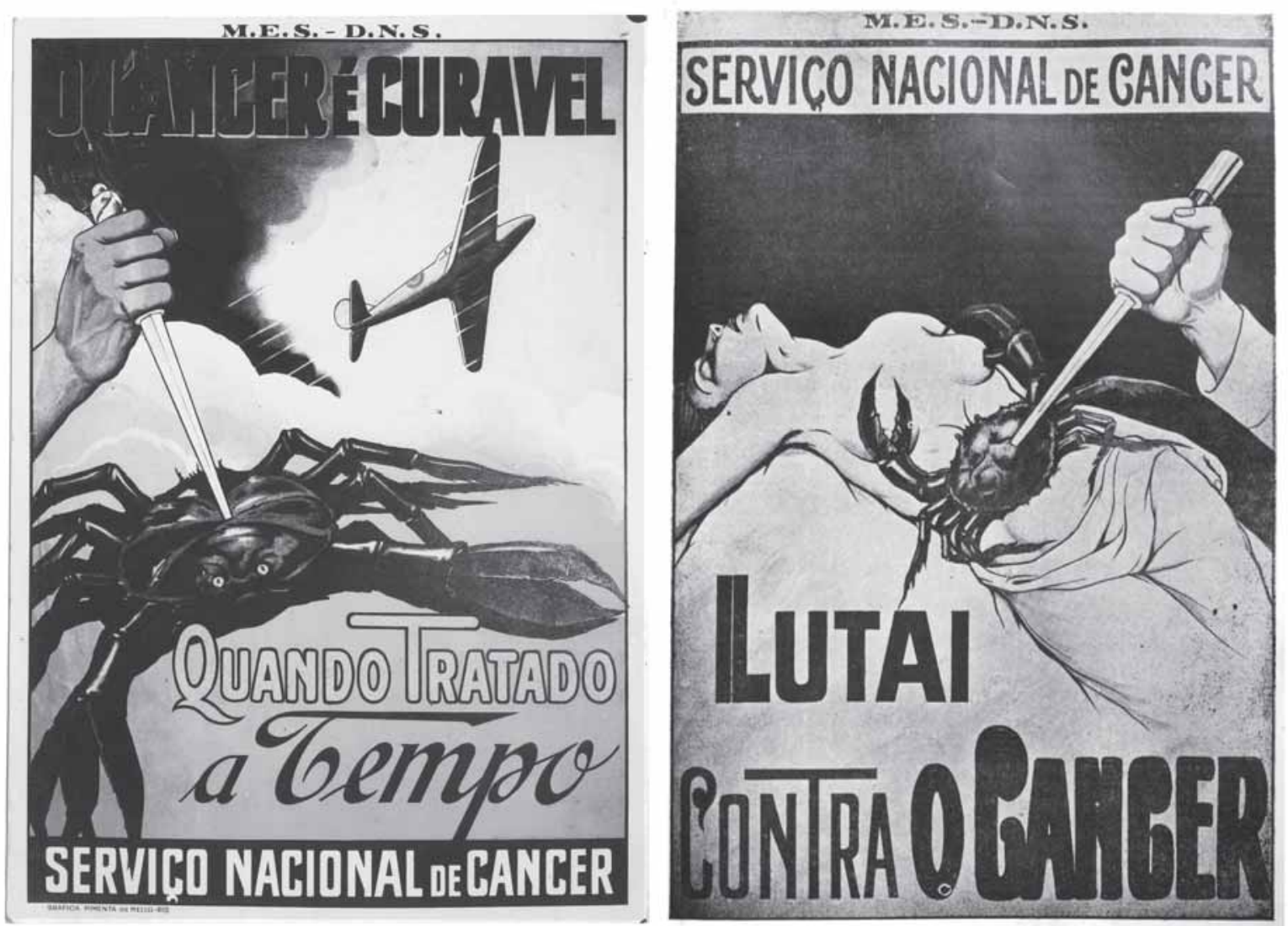

Figuras 2 e 3: Cartazes produzidos a partir de 1940. (acervo família Kroeff) 
educação em saúde era incentivada com a perspectiva de promover a cooperação da população no trabal ho dos agentes de saúde (Melo, 1981).

No final da década de 1960, a educação sanitária passou a ser denominada educação em saúde. É importante ressaltar que não se tratava apenas de uma mudança terminológica; tentava-se uma transformação conceitual. Além de levar informação sobre doenças e formas de prevenção, o olhar voltava-se para as condições de vida e saúde das populações.

Nesse período, as campanhas relacionadas ao câncer exploraram novos enfoques. As ideias de 'pavor' e 'morte anunciada', encontradas na maioria dos materiais educativos, foram, pouco a pouco, sendo substituídas por noções de que existiam recursos disponíveis e avanços no tratamento da doença. As campanhas buscavam alertar a sociedade sobre a moléstia, sem, contudo, alarmar a população. A ênfase na detecção precoce ganhou força, propiciada pelo progresso sobre o conhecimento da doença e pelos novos tratamentos.

A diretriz da promoção da saúde traz, no início dos anos 1990, o entendimento de saúde como consequência de fatores relacionados com a qualidade de vida, incluindo um padrão adequado de alimentação e nutrição, de habitação e saneamento, boas condições de trabalho, oportunidade de educação ao longo de toda a vida, ambiente físico limpo, apoio social para famílias e indivíduos, estilo de vida responsável e uma série de outros cuidados com a saúde (Buss, 2000). Promover saúde significa, então, a busca por melhores condições, por meio tanto de estratégias individuais quanto coletivas, envolvendo profissionais de saúde e cidadãos organizados em comunidade.

É nessa perspectiva que se inserem os materiais de campanha de prevenção do câncer elaborados a partir dos anos 1990. O foco, antes centrado no medo da doença, parece tender à ideia de val orização da vida. A percepção do risco ganha contornos amenizados, em especial nos materiais destinados à preven ção dos cânceres femininos (Figura 4). Os materiais impressos chamam a atenção para a necessidade de manter práticas saudáveis, tais como alimentação adequada, esportes, controle do tabagismo e estilo responsável de vida, no qual exames diagnósticos estão incluídos na agenda do dia (Figuras 5 e 6).

\section{Educação, comunicação, informação: interfaces das campanhas}

Os atuais índices de incidência da doença no Brasil revelam que o setor público, em colaboração com outros segmentos da sociedade, deve investir em campanhas de preven ção. Em recente estudo, Guerra e colaboradores (2005) investigaram a incidência de câncer, associando-o aos fatores de risco de adoecer, e constataram um aumento de diferentes tipos, como de estômago, boca, faringe, pulmões, colo do útero e próstata. A incidência de determinados tipos, muitas vezes, está relacionada a costumes alimentares, ao tabagismo, ao contato com vírus causadores de lesões, bem como à falta de exames preventivos, sem excluir os fatores genéticos.

Estudos recentes revelam o aumento do número de casos como consequência do modelo atual de sociedade, gerador de inúmeros problemas ambientais e de saúde. Desse modo, as campanhas preventivas continuam sendo fortes aliadas no controle da doença, fato que exige avaliação mais eficaz dessas iniciativas, bem como olhar crítico para os enfoques utilizados. 
Examinamos, até o momento, cartazes utilizados em campanhas no Brasil após 1940, elaborados por instituições como a Associação Paulista de Combate ao Câncer, o Instituto Português de Oncologia e o Serviço Nacional do Câncer, e cartazes produzidos a partir da década de 1990 sob orientação de órgãos ligados ao Ministério da Saúde como o Instituto Nacional do Câncer.

A análise dos cartazes de campanhas utilizados em diferentes períodos e sua relação com a história da educação em saúde no Brasil, realizada até o momento, permitiu identificar al gumas mensagens produzidas e, futuramente, pode trazer indícios de avanços e limites do uso desses materiais para a preven ção do câncer. Esses cartazes são uma rica fonte de consulta, depositada em órgãos públicos de saúde, que necessitam registros organizados por profissionais especializados na área da informação, em especial nas de arquivo e documentação.

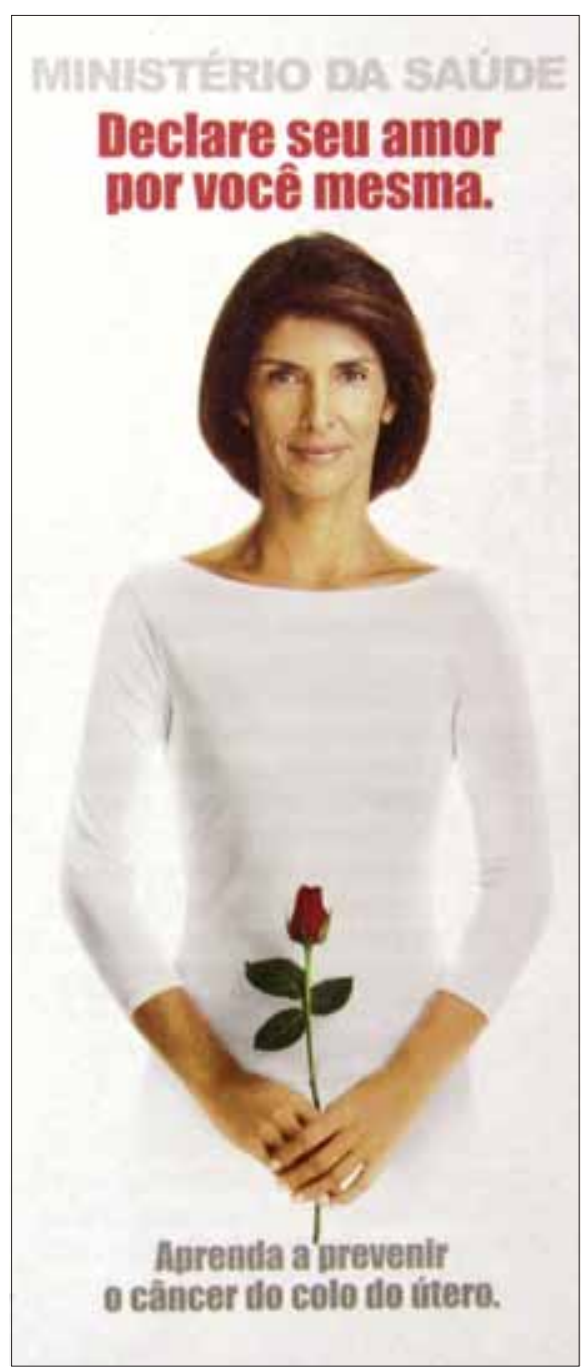

Figura 4: Cartaz de incentivo ao exame de colo de útero. (acervo Casa de Oswaldo Cruz)

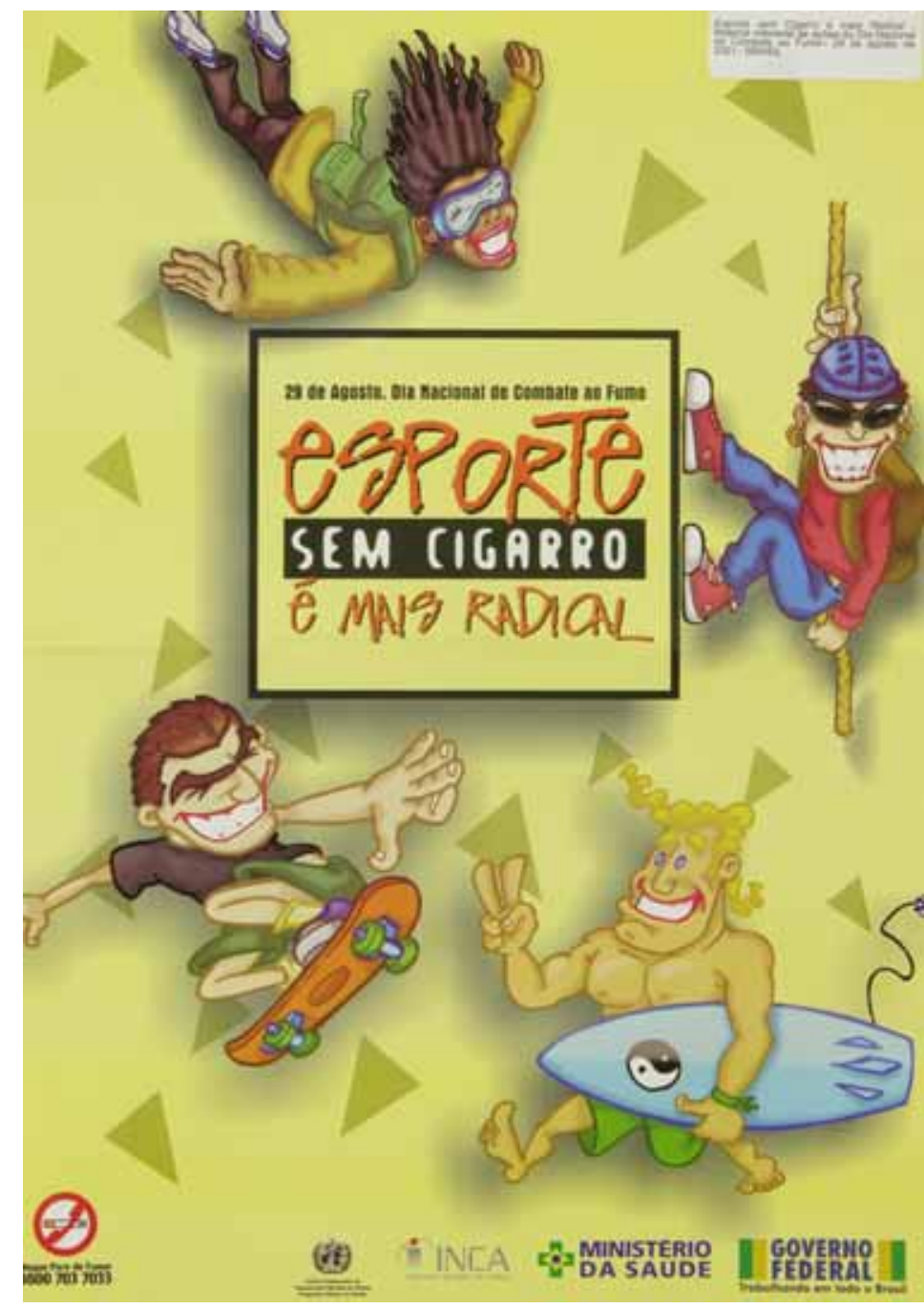

Figura 5: Cartaz de incentivo ao esporte e controle do tabagismo. (acervo Casa de Oswaldo Cruz) 


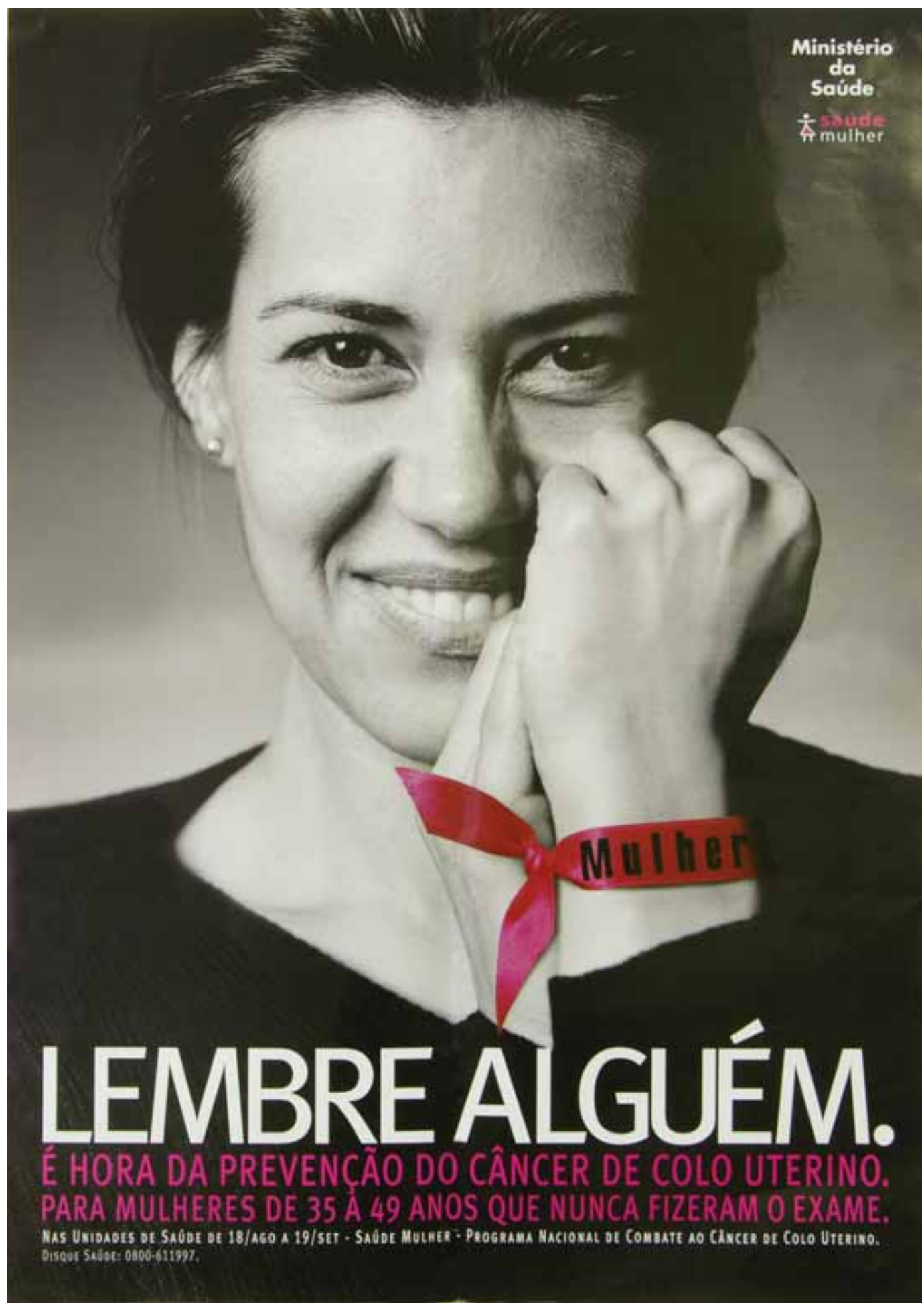

Figura 6: Cartaz de incentivo à elaboração de exames preventivos. (acervo Casa de Oswaldo Cruz) 
Os resultados encontrados indicam que esses materiais carecem de análises sob o olhar da comunicação, pois as linguagens utilizadas são bastante diversificadas nos cartazes e panfletos. Recentemente, a propaganda televisiva, a inserção do tema em programas de TV com grande audiência e as exposições, que envolvem o público pelos aspectos intelectual e emotivo, ganham força. Como exemplo de estratégia atual, em outubro de 2008 o Cristo Redentor, no alto do morro do Corcovado, observado à noite, ficava cor-de-rosa. Esse monumento e vários outros, localizados em diferentes regiões da cidade do Rio de Janeiro, receberam iluminação especial com o objetivo de alertar para a necessidade de realização de exames preventivos de câncer feminino. $O$ exemplo indica forte tendência no uso de diferenciadas estratégias de comunicação como forma criativa de conquistar audiência. No entanto, tais estratégias devem levar ao público informações confiáveis e comprometidas com pressupostos educativos, enfrentan do o desafio de promover campanhas com potencial de criar sentido a diferentes grupos da sociedade.

Por fim, evidenciamos nesta nota de pesquisa o desafio de associar as áreas de educação, comunicação e informação na análise das campanhas educativas mais recentes. Visamos, ao final da pesquisa, à produção de conhecimento no campo da educação em saúde que contribua para o desenvolvimento de futuras campanhas preventivas.

\section{REFERÊNCIAS}

BRASIL.

Ministério da Saúde. 10aㅡ Conferência Nacional de Saúde. Temas em Debate. Educação em saúde: histórico, conceitos e propostas. Conferência Nacional de Saúde Disponível em: http:// www.datasus.gov.br/cns/temas/educacaosaude/ educacaosaude.htm. Acesso em: 29 out. 2008. 1996.

BUSS, Paulo Marchiori.

Promoção da saúde e qualidade de vida. Ciência \& Saúde Coletiva, Rio de Janeiro, v.5, n.1, p.163-177. Disponível em: http:// www.scielo.br/pdf/csc/v5n1/7087.pdf. Acesso em: 07 maio. 2008. 2000.

CARVALHO, Alexandre Octavio Ribeiro de. O Instituto Nacional de Câncer e sua memória: uma contribuição ao estudo da invenção da cancerologia no Brasil. Dissertação (Mestrado) - Programa de Pós-graduação em História Política e Bens Culturais, Fundação Getulio Vargas, Rio de Janeiro. 2006.

FENELON, Sandro; ALMEIDA, Sidney de Souza.

A histórica visita de Marie Curie ao Instituto do Câncer de Belo Horizonte. Radiologia Brasileira, São Paulo, v.34, n.4. Disponível em: http://www.scielo.br/pdf/rb/v34n4/11242.pdf. Acesso em: 3 dez. 2008. 2001.

FONSECA, Cristina Oliveira.

Saúde no governo Vargas (1930-1945): dualidade institucional de um bem público. Rio de Janeiro: Editora Fiocruz. 2007.

GUERRA, Maximiliano Ribeiro et al.

Risco de câncer no Brasil: tendências e estudos epidemiológicos mais recentes. Revista Brasileira de Cancerologia, Rio de Janeiro, v.51, n.3, p.227-234. Disponível em: http://www.inca.gov.br/ rbc/n_51/v03/pdf/revisao1.pdf. Acesso em: 30 nov. 2008. 2005.

\section{KROEFF, Mário.}

Serviço Nacional do Câncer. Arquivos de Higiene, Rio de Janeiro, ano 17, n.3-4. 1947.

MELO, Joaquim Alberto Cardoso. Educação sanitária: uma visäo crítica. In: Canesqui, Ana Maria; Camargo, Elizabeth Silvares P. de; Barros, Maulisa Berti de (Org.). Educação e saúde. São Paulo: Cortez. p.28-43. (Cadernos do CEDES, 4). 1981.

MOHR Adriana; SCHALL, Virgínia Torres. Rumos da educação em saúde no Brasil e sua relação com a educação ambiental. Cadernos de Saúde Pública, Rio de Janeiro, v.8, n.2, p.199-203. Disponível em: http://www.scielosp. org/scielo.php/pdf. Acesso em: 21 abr. 2008. 1992. 
PETERSEN, Alan; LUPTON, Deborah.

The new plubic: health and self in the age of risk. Londres: Sage. 1996.

ROCHA, Heloisa Helena Pimenta.

Educação escolar e higienização da infância.

Caderno Cedes, Campinas, v.23, n.59, p.39-56.

Disponível em: http://www.cedes.unicamp.br.

Acesso em: 10 dez. 2008. 2003.

SCHALL, Virgínia Torres.

Alfabetizando o corpo: o pioneirismo de

Hortênsia de Hollanda na educação em saúde.
Cadernos de Saúde Pública, Rio de Janeiro, v.15, supl.2, p.149-159. Disponível em: http:// www.scielosp.org/pdf/csp/v8n2/v8n2a12.pdf. Acesso em: 19 maio. 2008. 1999.

TEIXEIRA, Luiz Antônio; FONSECA, Cristina Maria.

De doença desconhecida a problema de saúde pública: o INCA e o controle do câncer no Brasil. Rio de Janeiro: Ministério da Saúde. 2007.

\section{u UuUUU}

